\title{
Raised urea clearance in cirrhotic patients with high uric acid clearance is related to low salt excretion
}

\author{
G Decaux, F Prospert, B Namias, M Schlesser, A Soupart
}

\begin{abstract}
In cirrhotic patients without renal failure, salt retention could result from a decreased effective intravascular volume or could be a primary event leading to increased intravascular volume. Clearance of urea and uric acid depend on an effective intravascular volume. In the syndrome of inappropriate secretion of antidiuretic hormone (SIADH) - a state of increased intravascular volume - uric acid clearance is increased and that of urea is increased only when salt excretion is low. The intravascular volume of 60 consecutive cirrhotic patients without renal failure was estimated indirectly by studying the relationship between fractional excretion of filtered (FE) sodium, urea, and uric acid. Forty five per cent had a high FE uric acid ( $>12 \%)$, which could mean a high intravascular volume, and presented with an FE urea that was inversely correlated with $F E$ sodium $(r=-0,62$; $\mathbf{p}<\mathbf{0 . 0 0 1}$ ) as in SIADH, while in the controls the FE urea was positively correlated with FE sodium $(r=+0,46 ; p<0.01)$. In patients who had a normal FE uric acid and low FE sodium $(<0 \cdot 2 \%)$, the FE urea was significantly lower $(40(13) \%, n=20)$ than in subjects with high FE uric acid and a low FE sodium (61 (9)\%, $n=16$, $\mathbf{p}<0.001)$; this last group also presented with lower mean blood urea concentrations (3.1 $(1.2) \mathrm{mmol} / \mathrm{l}$ and $4.0(1.8) \mathrm{mmol} / \mathrm{l} ; \mathrm{p}<0.05)$ and a lower supine renin activity $(p<0.01)$. As observed in the SIADH, cirrhotic patient with high FE uric acid have raised FE urea only when salt excretion is low. It is believed that the low salt excretion is not caused by a decrease in effective intravascular volume and that this is increased in cirrhotic patients with raised $F E$ uric acid.
\end{abstract}

(Gut 1992; 33: 1105-1108)

Research Unit for the Study of Hydromineral Metabolism, Department of Internal Medicine, University Hospital

Erasme, Free University

of Brussels, Brussels,

Belgium

G Decaux

F Prospert

B Namias

M Schlesser

A Soupart

Correspondence to:

DrG Decaux, Service de

Médecine Interne, Hôpital

Erasme, 808 Route de Lennik,

1070 Brussels, Belgium

Accepted for publication

6 December 199
We have suggested, as described in the syndrome of inappropriate secretion of anti-diuretic hormone (SIADH), ${ }^{1-+}$ that the high uric acid ${ }^{5}$ and high urea clearances ${ }^{6}$ frequently observed in cirrhosis could be related to an increased effective intravascular volume,${ }^{6}$ the so called 'overflow theory' of ascites formation.' In our previous studies a high uric acid clearance was observed in 30 to $50 \%$ of our cirrhotic patients. ${ }^{689}$ However, high urea clearances have been less frequently observed. ${ }^{6}$

We have also reported recently that in the SIADH urea clearance is less frequently increased than that of uric acid. ${ }^{10}$ In fact, high urea clearance was present only with concomitant low salt excretion and the fractional excretion of filtered (FE) urea was negatively correlated with FE sodium, whereas the FE uric acid was not dependent on the sodium excretion. ${ }^{10}$

Similarly, we investigated in this study the potential relationship between FE urea and FE sodium in cirrhotic patients with high and with normal FE uric acid.

Our results indicate that a negative correlation between $\mathrm{FE}$ urea and $\mathrm{FE} \mathrm{Na}$ is present only in cirrhotic patients with a high FE uric acid. This finding supports the concept that in cirrhosis with high FE uric acid the intravascular volume is increased (the 'overflow' theory ${ }^{7}$ ) as in the SIADH. ${ }^{112}$

\section{Patients and methods}

We analysed retrospectively the scores of all patients admitted to hospital with cirrhosis over a four year period. Sixty patients (mean (SD) age, 52 (14) years) with normal renal function and with histologically proved liver cirrhosis were available for investigation. In all the patients, the serum creatinine concentration was lower or equal to $1 \cdot 1 \mathrm{mg} / \mathrm{dl}$ (upper limit of normal $\leq 1 \cdot 2 \mathrm{mg} / \mathrm{dl}$ ) and the blood bicarbonate concentration was higher than $22 \mathrm{mmol} / \mathrm{l}$; none had diabetes, glycosuria, phosphaturia, or proteinuria. All the patients were in a stable clinical condition, had had no medication for at least one week, and were eating a normal hospital diet (50 to $150 \mathrm{mmol}$ sodium/day), except for 33 with ascites, who were on a low salt diet $(20 \mathrm{mmol}$ sodium/day). None of the patients had signs of hepatic encephalopathy or evidence of infection, and none had a history of recent gastrointestinal bleeding. Only patients with a total bilirubin concentration lower than $3 \mathrm{mg} / \mathrm{dl}$ were studied. Measurements were made after at least one week of a stable hospital diet. Measurement of supine renin activity was available in 16 ascitic patients with low salt excretion (FE $\mathrm{Na}<0 \cdot 2 \%$ ).

The percentages of FE urea, FE uric acid, and FE Na were calculated as the urine/serum urea, uric acid, or sodium concentration divided by urine/serum creatinine concentration $\times 100$. Urine samples from patients, who had fasted overnight, were collected between 8 and $10 \mathrm{am}$. Blood samples were drawn at 9 am. The same measurements were performed in 40 controls of a similar age and sex-in 17 of whom, measurements were performed after four days of a low salt $(20 \mathrm{mmol} /$ day $\mathrm{Na})$ diet.

All serum and chemical measurements were performed in the hospital clinical laboratory. Uric acid was measured by the Uricase method. ${ }^{13}$

Statistical analysis was performed by using the unpaired Student's $t$ test, the Wilcoxon test, and linear regression calculations. ${ }^{1+}$ 
TABLE I Mean (SD) data in 60 patients with cirrhosis grouped according to their fractional uric acid excretion (FE uric)

\begin{tabular}{|c|c|c|c|}
\hline & Cirrhosis without ascites & Cirrhosis with ascites & Cirrhosis with and without ascites \\
\hline $\begin{array}{l}\text { Investigation } \\
\text { (control range) }\end{array}$ & $\begin{array}{c}F E \underset{(n=16)}{\text { uric }}<12 \% \\
\text { FE uric } \geqslant 12 \% \\
(n=11)\end{array}$ & $\underset{(n=17)}{F E \underset{\text { uric }}{ }<12 \%} \quad \underset{(n=16)}{F E \text { uric } \geq 12 \%}$ & $\underset{(n=33)}{F E \underset{(n=27)}{\text { uric }}<12 \%} \quad \underset{(2)}{\text { uric } \geq 12 \%}$ \\
\hline Serum $\mathrm{Na}$ & $138.0(2 \cdot 5) \quad 137.0(2 \cdot 2)$ & $133.0(4.7) \quad \mathrm{NS}=$ & $135.0 \quad \underbrace{(3.5)}_{N S} 134.6(4.3)$ \\
\hline $\begin{array}{l}\text { Blood urea } \\
(3 \cdot 5-7 \mathrm{mmol} / \mathrm{l})\end{array}$ & $3.7(1.4)=3.5(1.6)$ & 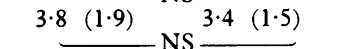 & $3.75(1.6) \quad \mathrm{NS}^{3.4(1.5)}$ \\
\hline $\begin{array}{l}\text { Uric acid } \\
(2 \cdot 5-7.5 \mathrm{mg} / \mathrm{dl})\end{array}$ & $5.3(1.2) \quad p<0.01$ & $5.2(1.6) \quad p<0.01$ & $5.2(1.4) \quad p<0.001 \quad 3.5 \quad(0.8)$ \\
\hline $\begin{array}{l}\text { Creatinine clearance } \\
(50-160 \mathrm{ml} / \mathrm{min})\end{array}$ & $85.0 \quad(25) \quad \mathrm{NS}-80.0 \quad(21)$ & $82 \cdot 0(24)-{ }^{78.0(20)}$ & $84 \cdot 0(24)-79 \cdot 0 \quad(20)$ \\
\hline $\begin{array}{l}\text { FE uric acid } \\
(3 \cdot 5-11 \cdot 9 \%)\end{array}$ & $15.0(3.5)$ & $15 \cdot 3(4 \cdot 0)$ & $15 \cdot 1(0 \cdot 4)$ \\
\hline $\begin{array}{l}\text { FE urea } \\
(25-55 \%)\end{array}$ & $43.5 \underbrace{(9.6)} \mathrm{p}<0.06$ & $40 . \underbrace{(12.9)} \begin{array}{r}53.4 \quad(13.3) \\
p<0.01\end{array}$ & 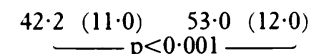 \\
\hline $\begin{array}{l}\text { V/Cl creat } \times 100 \\
(0 \cdot 25-1 \cdot 1 \%)\end{array}$ & 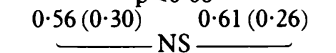 & 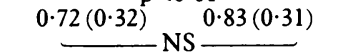 & 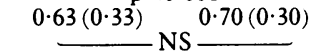 \\
\hline $\begin{array}{l}\text { FE Osm } \\
(0 \cdot 7-2 \cdot 8 \%)\end{array}$ & $1 . \underbrace{29(0.65)} \mathrm{NS} \stackrel{1.30(0.54)}{ }$ & $1 \cdot \underbrace{12(0.36)} \mathrm{NS} \stackrel{1.45(0.54)}{ }$ & 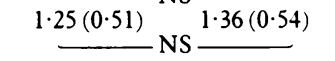 \\
\hline
\end{tabular}

Values for control subjects are ranges. Abbreviations: $\mathrm{V}=$ urine volume; $\mathrm{Cl}$ creat $=$ creatinine clearance

\section{Results}

Table I shows that the group of patients with or without ascites and with a high FE uric acid $(\geq 12 \%)$ had a higher FE urea than the control group or the cirrhotic patients with a normal FE uric acid. Supine and orthostatic blood pressure and pulse rate, as well as biochemical findings reflecting the degree of liver failure (serum aspartate and alanine aminotransferase activities, total bilirubin concentration, prothrombin time, and albumin concentration) were similar in patients with high or normal FE uric acid values. The higher FE urea (about 10\%) in the patients with a high FE uric acid could not be explained by a raised urine flow rate. Mean blood urea concentration was about $10 \%$ lower in patients with high FE uric acid but this did not reach statistical significance. When the patients with a high FE uric acid were studied separately, we observed an inverse correlation between the FE urea and $\mathrm{FE} \mathrm{Na}$ in those who did not have ascites $(\mathrm{r}=-0,53 ; \mathrm{n}=11 ; \mathrm{p}<0 \cdot 10)$ and those ascites $(r=-0,66 ; n=16 ; p<0.01)$, and in both groups when the results are pooled $(\mathrm{r}=-0,62$; $\mathrm{n}=27 ; \mathrm{p}<0 \cdot 001-$ Figure).
In the patients with normal FE uric acid no significant correlation was observed between $\mathrm{FE}$ urea and $\mathrm{FE} \mathrm{Na}(\mathrm{r}=+0 \cdot 20 ; \mathrm{n}=33)$. In the control subjects a positive correlation was found between $\mathrm{FE} \mathrm{Na}$ and $\mathrm{FE}$ urea $(\mathrm{r}=+0,46$; $\mathrm{p}<0.01)$. It must be noted that four cirrhotic patients with ascites and a high FE uric acid also had relatively high salt excretion (FE $\mathrm{Na}>0 \cdot 5 \%$ ) as noted in three patients in the group with normal FE uric acid (Figure).

In the cirrhotic patients without ascites and a high FE uric acid, four patients had very low salt excretion (FE $\mathrm{Na}<0 \cdot 2 \%$ ) and in the group with normal FE uric acid, eight had a FE $\mathrm{Na}<0 \cdot 2 \%$.

When the cirrhotic patients with low $\mathrm{FE} \mathrm{Na}$ $(<0 \cdot 2 \%)$ and normal FE uric acid where compared with the normal subjects with a similarly low $\mathrm{FE} \mathrm{Na}$, there was no significant difference in the FE urea (40 (13)\% and $37(8) \%$; NS) while the cirrhotic patients with high FE uric acid $(\geq 12 \%)$ and low FE Na $(<0 \cdot 2 \%)$ had a significantly higher FE urea than the normal subjects or the cirrhotic patients with normal FE uric acid (FE urea 61 (9)\%; p<0.001) (Table II). These

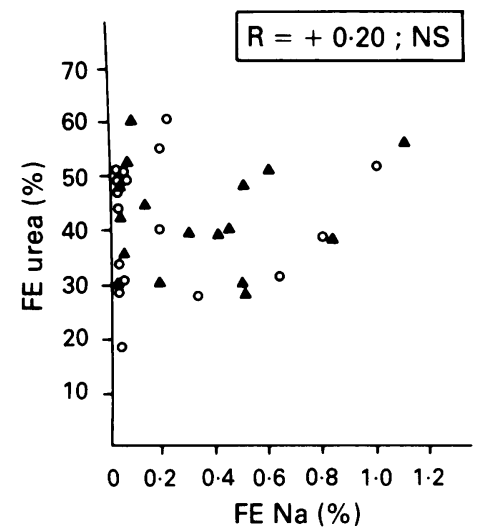

Cirrhotic patients with FE uric acid $<12 \%$

- Cirrhotic without ascites $(n=16)$ - Cirrhosis with ascites $(n=17)$

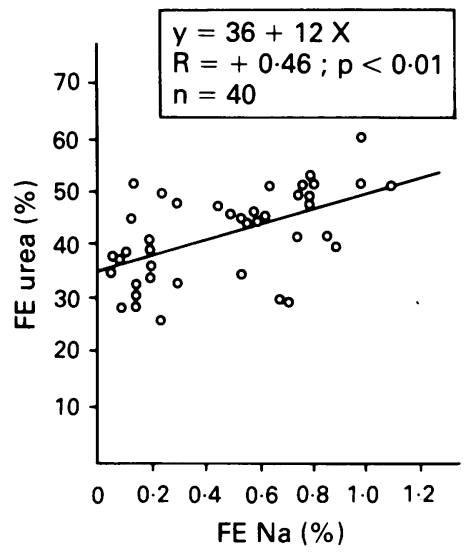

Control subjects $(n=40$ )

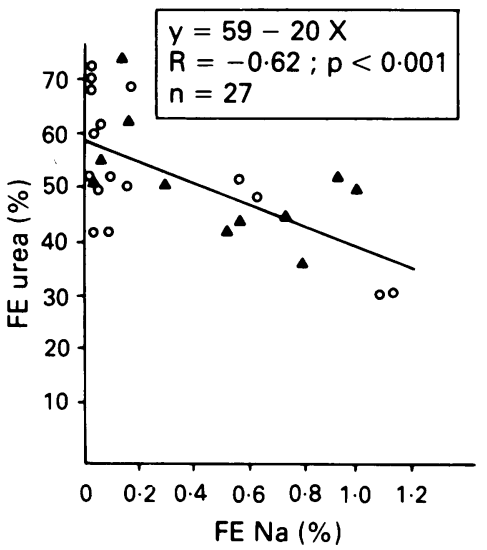

Cirrhotic patients with FE uric acid $\geqslant 12 \%$

The urea/creatinine clearance ratio (FE urea) in relation to FE Na measured in 27 cirrhotic patients with $(O)$ and zithout $(\boldsymbol{\Delta})$ ascites and a high $F E$ uric acid $(\geqslant 12 \%)$ (right panel). The same relationship in normal subjects (middle panel) and in cirrhotic patients with normal FE uric acid (left panel). 
TABLE II Patients with a low FE Na $(<0 \cdot 2 \%)(n=36)$ grouped according to FE uric acid $(<12 \%$ group I, $\geq 12 \%$ group II) and whether or not they had ascites

\begin{tabular}{|c|c|c|c|c|}
\hline & \multicolumn{2}{|c|}{ Cirrhosis without ascites } & Cirrhosis with ascites & Cirrhosis with and without ascites \\
\hline & $\begin{array}{c}F E \underset{(n=8)}{\text { uric }}<12 \% \\
(n=8\end{array}$ & $\begin{array}{c}F E \text { uric } \geqslant 12 \% \\
(n=4)\end{array}$ & 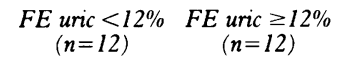 & $\begin{array}{cc}F E \text { uric }<12 \% \\
(n=20)\end{array} \quad \begin{array}{c}F E \text { uric } \geq 12 \% \\
(n=16)\end{array}$ \\
\hline $\begin{array}{l}\text { Serum Na } \\
(\mathrm{mmol} / \mathrm{l})\end{array}$ & $137 \cdot 0 \quad(2)$ & $138 \cdot 0$ & $133 \cdot \underbrace{(6)} \mathrm{NS} \stackrel{132 \cdot 0 \quad(3 \cdot 4)}{ }$ & $134 \cdot 0 \quad \underbrace{(5)} \mathrm{NS} \stackrel{134 \cdot 0(3 \cdot 5)}{ }$ \\
\hline $\begin{array}{l}\text { Urea } \\
(\mathrm{mmol} / \mathrm{l})\end{array}$ & $3 \cdot 7(1 \cdot 3)$ & $2 \cdot 6(0 \cdot 7)$ & $4 \cdot \underbrace{(1.8)} \mathrm{p}<0 \cdot 10$ & $4.0 \underbrace{(1.8)} \mathrm{p}<0.05 \underline{3.1 \quad(1.2)}$ \\
\hline $\begin{array}{l}\text { Uric acid } \\
(\mathrm{mmol} / \mathrm{l})\end{array}$ & $0.32(0.7)$ & $0 \cdot 20(0 \cdot 4)$ & $0 . \underbrace{33(0.11)} 0.18(0.04)$ & $0 . \underbrace{32(0.09)}_{\mathrm{p}<0.001} 0.18(0.04)$ \\
\hline $\begin{array}{l}\text { Creatinine clearance } \\
(\mathrm{ml} / \mathrm{min})\end{array}$ & $77 \cdot 0 \quad(18)$ & $71 \cdot 0 \quad(16)$ & $74 \cdot 0(17) \quad \mathrm{NS} \stackrel{70 \cdot 0(17)}{ }$ & 75.0 (18) $\mathrm{NS}$ \\
\hline $\begin{array}{l}\text { FE urea } \\
(\%)\end{array}$ & $41 \cdot 0 \quad(13)$ & $63 \cdot 0(10)$ & $40.0 \underbrace{(12)} \mathrm{p}<0.01 .0 \quad(10)$ & $40.0(13) \quad 61 \cdot 0 \quad(9)$ \\
\hline$\underset{(\%)}{\mathrm{FE} \mathrm{Na}}$ & $0 \cdot 1 \quad(0 \cdot 06)$ & $0.08(0.05)$ & 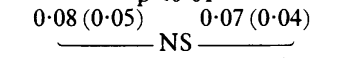 & $\underline{0.08(0.06)} \mathrm{NS} \stackrel{0.07(0.05)}{ }$ \\
\hline$\underset{(\%)}{\text { FE uric acid }}$ & $6 \cdot 1 \quad(1 \cdot 6)$ & $16 \cdot 7(5 \cdot 2)$ & $6.4(1.6) \quad 16.0(4.8)$ & $16 \cdot 4(4 \cdot 7)$ \\
\hline $\mathrm{V} / \mathrm{Cl}$ creat & $0 \cdot 6(0 \cdot 2)$ & $0 \cdot 7(0 \cdot 2)$ & $0.68(0.2)$ & NSS $0.7 \quad(0.2)$ \\
\hline $\begin{array}{l}\mathrm{RA} \\
\text { (ng AI/ml/h) }\end{array}$ & & & 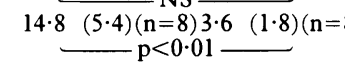 & \\
\hline
\end{tabular}

Uric acid: conversion factor in $\mathrm{mg} / \mathrm{dl}=\mathrm{mmol} / \mathrm{l}: 0 \cdot 059 . \mathrm{RA}=$ renin activity.

cirrhotic patients with a low FE Na and a high FE uric acid also had a mean blood urea concentration that was lower than that of patients with low FE $\mathrm{Na}$ and normal FE uric acid $(3 \cdot 1$ $(1 \cdot 2) \mathrm{mmol} / \mathrm{l}$ and $4.0(1.8) ; \mathrm{p}<0.05)$. Supine renin activity, measured in eight ascitic patients in each group (Table II), was significantly higher in the patients with a normal FE uric acid $(\mathrm{p}<0.01)$.

The FE uric acid was not significantly correlated with the FE $\mathrm{Na}$ in any group.

\section{Discussion}

Hypouraemia in cirrhosis could be the result of a decreased production ${ }^{15}$ and/or an increased clearance of urea. ${ }^{6}$ As expected, the absolute excretion of urea did not differ between the groups with a normal FE uric acid $(0.13 \mathrm{mmol} /$ minute) and a high FE uric acid $(0.14 \mathrm{mmol} /$ minute), although it was lower than in control subjects $(0.20 \mathrm{mmol} / \mathrm{minute})$. This suggests that urea production and protein intake were similar in both groups, and it is therefore unlikely that the patients with a normal FE urea were eating a lower protein diet (known to decrease the FE urea) than those with a high FE urea. ${ }^{16}$ In our two groups of cirrhotic patients (those with a normal and those with a high FE uric acid), the difference in FE urea could not be related to a difference in the urine flow rate or creatinine clearance as these were similar. ${ }^{17}$

The last known factor that might cause a high FE urea is an increased effective intravascular volume ${ }^{+6}$ the clinical assessment of which is of low sensitivity and specificity. ${ }^{18}$ Supine and orthostatic blood pressure and pulse rate were not significantly different between both groups. Interestingly, we observed an inverse correlation between the FE urea and FE $\mathrm{Na}$ only in those patients with a high FE uric acid.

We have recently reported the same phenomenon in patients with hyponatraemia related to SIADH. ${ }^{10}$ In these patients FE uric acid is classically high but FE urea is increased only when salt excretion is low..$^{10}$ In the cirrhotic patients with a low FE Na $(<0 \cdot 2 \%)$, those with a high FE uric acid showed a higher FE urea
$( \pm 20 \%)$ and a lower mean blood urea concentration $( \pm 20 \%)$ than that cirrhotic patients with a normal FE uric acid (Figure and Table II).

This low salt excretion (mostly secondary to low salt intake) would primarily suggest a trend to 'hypovolaemia'. However, if the effective intravascular volume was really decreased in these patients we would expect a trend to a low FE urea ${ }^{19}$ as observed in our controls or in our cirrhotic patients with normal FE uric acid.

We observed, in a few cirrhotic patients with ascites, spontaneously high salt excretion (FE $\mathrm{Na}>0.5 \%$ - see Figure) despite salt restriction. This is not an infrequent observation in cirrhosis with ascites. ${ }^{20}$ It is possible that the various salt retaining stimuli could be blunted as a consequence of an improvement in liver function during the hospital stay, an improvement that could not, however, be demonstrated by routine laboratory tests (aminopyrine breath test was not available). ${ }^{21} 22$ This may be observed without a change in creatinine clearance. ${ }^{22} 23$

Moreover, some of our cirrhotic patients without ascites and normal salt intake were retaining salt (low FE $\mathrm{Na}<0 \cdot 2 \%$ ). The reason for the low FE $\mathrm{Na}$ observed in some patients with normal FE uric acid could be a trend to hypovolaemia. Their normal or low FE urea is an expected finding. However, in the group without ascites and high FE uric acid, four patients had a low FE Na $(<0.2 \%)$ despite normal salt intake. The salt retention in these patients (and in the other ascitic patients with high FE uric acid) was associated with, a high FE urea (Figure) which suggests a normal or increased effective intravascular volume. ${ }^{10}$ Renin activity was measured in 16 ascitic patients: those with a high FE uric acid $(\geqslant 12 \%)$ had a significantly lower renin activity than the cirrhotic patients with normal FE uric acid, although this was associated with very low salt excretion in each group (mean FE $\mathrm{Na} 0.07 \%$ and $0.08 \%$ ). This suggests a different intravascular volume in these groups. Some believe that salt retention (at least in the initial stages) in many cirrhotic patients without renal failure is not related to a decrease in the effective vascular volume, ${ }^{72}$ but is due to liver cirrhosis itself, mainly intrasinusoidal hypertension, ${ }^{25}$ 
that leads to an increase in the effective vascular volume. The portal hypertension localises accumulation of the retained sodium and water to the peritoneal cavity. In the group of cirrhotic patients with normal FE uric acid, we observed normal urea clearance that did not seem to be dependent on salt excretion, while in the patients with high FE uric acid, urea clearance was highly correlated with salt excretion. One explanation for this relationship could be that the kidney compensates for the lack of urine osmotic charge in these cirrhotic patients with low salt excretion that is not secondary to a decrease in effective volaemia, by increasing urea excretion. The underlying mechanism of this remains to be established.

It is known that expansion induced by saline infusion in humans increases the clearance of uric acid, and that this is only related to the infused volume and not to the sodium load or serum sodium concentration ${ }^{26}$; this could explain the lack of significant correlation between FE uric acid and $\mathrm{FE} \mathrm{Na}$ in our patients.

Another hypothesis would be that the raised $\mathrm{FE}$ urea and FE uric acid result from a renal tubule abnormality induced by the cirrhotic state. Although urea-losing nephropathy has never been reported, this could theoretically exist. The fact that the high FE urea is observed only when salt excretion is low, however, seems to be less compatible with a tubulopathy.

We believe that the patients with salt retention and normal FE uric acid correspond to the 'underfilling theory' 2728 while those with high uric acid clearance reflect the 'overflow theory'. ${ }^{2+}$ These two theories are probably not incompatible with each other. ${ }^{29} 30$

This work was supported by a grant from the FNRS $(1.5 .204 .91 \mathrm{~F})$

1 Dorhout Mees EJ, Blom van Assendelf TP, Nieuwenhuis MG. Elevation of uric acid clearance caused by inappropriate antidiuretic hormone secretion. Acta Med Scand 1971; 189: antidius.

2 Beck LH. Hypouricemia in the syndrome of inappropriate secretion of antidiuretic hormone. N Engl f Med 1979; 301: $528-30$

3 Decaux G, Dumont I, Waterlot Y, Hanson B. Mechanisms of hypouricemia in the syndrome of inappropriate secretion of antidiuretic hormone. Nephron 1985; 39: 164-8.

4 Decaux G, Genette F, Mockel J. Hypouremia in the syndrome of inappropriate secretion of antidiuretic hormone. Ann Intern Med 1980; 93: 716-7.

5 Michelis MF, Warms PC, Fusco RD, Davis BB. Hypouricemia and hyperuricosuria in Leannec's cirrhosis. Arch Intern Med 1974; 134: 681-3.

6 Decaux G, Dumont I, Naieje N, Mols P, Melot C, Mockel J. High uric acid and urea clearance in cirrhosis secondary to an increased 'effective vascular volume'. Am F Med 1982; 73: 328-34.

7 Lieberman FL, Denison EK, Reynolds TB. The relationship of plasma volume, portal hypertension, ascites and renal sodium retention in cirrhosis: the overflow theory of ascites sodium retention in cirrhosis: the overfow theory
formation. Ann NY Acad Sci 1970; 170: 202-12.

8 Decaux G, Mols P, Naieje R, Reding P. Hypouricemia in cirrhosis reflects hemodynamic alterations. Metabolism cirrhosis reflects

9 Decaux G, Hanson B, Cauchie P, Bosson D, Unger J. Relationship between aldosterone and sodium, potassium and uric acid clearance in cirrhosis with and without ascites. Nephron 1986; 44: 226-9.

10 Decaux G, Prospert F, Cauchie P, Soupart A. Dissociation between uric acid and urea clearances in the syndrome of inappropriate secretion of antidiuretic hormone related to salt excretion. Clin Science 1990; 78: 451-5.

11 Bartter FC. The syndrome of inappropriate secretion of antidiuretic hormone (SIADH). DM 1973; 1-47.

12 Verbalis JG, Drutarosky MD, Ertel RJ, Vollmer RR. Adaptive responses to sustained volume expansion in Adaptive responses to sustained volume expansior

13 Lidolle L, Seegmitter JE, Laster L. Enzymatic spectrophotometric method for determination of uric acid. $\mathcal{J} L a b$ Clin Med 1959; 54: 903-13.

14 Swinscow TDV. Statistics at square one. London: British Medical Association, 1978

15 Galambos JT. Evaluation and therapy of ascites. In: Smith LH, ed. Major problems in internal medicine. Vol 17. Philadelphia: WB Saunders, 1979: 323-56.

16 Murdaugh HV, Schmidt-Nielsen B, Doyle EM, O'Dell R. Renal tubular regulation of urea excretion in man. $\mathcal{F} A p p$ Physiol 1958; 13: 263-8.

17 Shannon JA. Glomerular filtration and urea excretion in relation to urine flow in the dog. Am F Physiol 1936; 117 : $206-25$

18 Chung HM, Kluge R, Schrier RW, Anderson RJ. Clinical assessment of extracellular fluid volume in hyponatremia. assessment of extracellular

19 Dossetor JB. Creatinine versus uremia: the relative significance of blood urea nitrogen and serum creatinine concentration in azotemia. Ann Intern Med 1966; 65: 1287-9.

20 Conn HO: The rational management of ascites. In: Popper $\mathrm{H}$ Schaffer R, eds. Progress in liver disease. 4th ed. New York Grune \& Stratton, 1972: 269-88.

21 Wensing G, Sabra R, Branch RA. The onset of sodium retention in experimental cirrhosis in rats is related to a critical threshold of liver function. Hepatology 1990; 11: 779-86.

22 Wensing G, Branch RA. Phenobarbital influences the development of sodium retention in liver disease induced by bile duct ligation in the rat. Hepatology 1990; 11: 773-8.

23 Ohno T, Sabra R, Branch RA. Sodium retention and hepatic function after two-thirds hepatectomy in the rat. Hepatolog $1991 ; 14: 511-7$

24 Levy $M$. Sodium retention and ascites formation in dogs with experimental portal cirrhosis. Am $\mathcal{F}$ Physiol 1977; 233: F572-85

25 Unikousky B, Wexler MJ, Levy M. Dogs with experimenta cirrhosis of the liver but without intrahepatic hypertension do not retain sodium or form ascites. 7 Clin Invest 1983; 72 : 1594-604.

26 Diamond $\mathbf{H}$, Meesel A. Influence of volume expansion, serum sodium and fractional excretion of sodium on urate excretion. Pflugers Arch 1975; 356: 47-57.

27 Epstein M Deranged sodium homeostasis in cirrhosis. Gastroenterology 1979; 76: 622-35.

28 Bichet DG, Groves BM, Schier RW. Mechanisms of improvement of water and sodium excretion by immersion in decompesated cirrhotic patients. Kidney Int 1983; 24 788-94.

29 Schrier RW, Arroyo V, Bernardi M, Epstein M, Henrikson JH, Rodés J. Peripheral arterial vasodilatation hypothesis: proposal for the initiation of renal sodium and water retention in cirrhosis. Hepatology 1988; 8: 1151-7.

30 Rocco VK, Ware AJ. Cirrhotic Ascites. Pathophysiology, diagnosis and management. Ann Intern Med 1986; 105: $573-85$. 